\begin{tabular}{l} 
Sharif University of Technology \\
Scientia Iranica \\
SCIENTIA \\
IRAN \\
Thanstions A: Civil Engineering \\
\hline
\end{tabular}

\title{
Effects of initial suction and degree of saturation on dynamic properties of sand at large strain
}

\author{
F. Jafarzadeh, A. Ahmadinezhad*, and H. Sadeghi \\ Department of Civil Engineering, Sharif University of Technology, Tehran, Iran.
}

Received 14 December 2018; received in revised form 14 June 2019; accepted 4 August 2019

\section{KEYWORDS}

Cyclic simple shear; Suction;

Degree of saturation;

Shear modulus;

Damping ratio;

Unsaturated sand.

\begin{abstract}
Soil deposits may experience different hydraulic states in terms of suction $(\psi)$ and saturation degree $\left(S_{r}\right)$ while being subjected to large strain caused by dynamic loading during earthquakes. This phenomenon was investigated by considering the effects of initial $\psi$, initial $\left(S_{r}\right.$, sample preparation method, drainage condition, and cycle number $(N)$ on dynamic properties. Shear modulus $(G)$ and damping ratio $(D)$ were specifically studied for unsaturated sand using a modified cyclic simple shear device for all zones of Soil Water Retention Curve (SWRC). Results revealed the relative significance of both $\psi$ and $S_{r}$ in relation to SWRC on observed trends in $G$ and $D$. Based on the analysis of some results in the literature, it was shown that most of the data followed a sigmoid function on the plane of normalized stiffness $\left(G / G_{\text {sat }}\right)$ versus the suction normalized to the air entry value. It was also revealed that minimum damping was not in conjunction with maximum stiffness due to the contribution of other mechanisms in damping like inter-particle water lubrication. The comparison between results of two testing methods indicated the notable influence of initial fabric on $G$. Furthermore, the overall trends in $G$ and $D$ against $N$ were marginally influenced by initial $\psi$ and $S_{r}$.
\end{abstract}

(C) 2021 Sharif University of Technology. All rights reserved.

\section{Introduction}

Natural soil deposits as well as engineered earth-fill structures are mostly in unsaturated states [1]. This dominant natural field condition, therefore, necessities investigating the dynamic soil properties of unsaturated soils $[2,3]$. In the context of unsaturated soil mechanics, there are two state parameters, namely suction $(\psi)$ and saturation degree $\left(S_{r}\right)$, which significantly affect the mechanical behavior of unsaturated soils in addition to other factors documented in classical soil mechanics for saturated soils like effective stress and

*. Corresponding author. Tel.: +982166164226

E-mail addresses: fardin@sharif.edu (F. Jafarzadeh);

adel.ahmadinezhad88@student.sharif.edu and

ahmadinezhad_adel@yahoo.com (A. Ahmadinezhad);

hsadeghi@sharif.edu (H. Sadeghi) void ratio [4]. Depending on the annual variations in regional climate and groundwater table, soil layers at different depths experience different values of these parameters from potentially fully saturated to nearly dry states [2]. The importance of reliable assessment of in-situ hydraulic state has been supported by recent advancements in direct measurement of soil water potential at arbitrary depths [5]. As a result, it is essential to consider all the possible hydraulic conditions when simulating in-situ soil elements subjected to dynamic loading at laboratory for a more reliable assessment.

Two laboratory methods are used in general for controlling and simulating various hydraulic states of an unsaturated soil specimen including:

1. Control of compaction water content ( $w$-con trolled);

2. Control of suction ( $\psi$-controlled).

The first method enjoys the merit of being quick and 
it leads to different conditions in terms of not only hydraulic state but also soil fabric. Therefore, the behavior of test specimens prepared in this way may not be ideally comparable purely based on their different hydraulic states as a consequence of different fabrics [6]. This is because soil fabric could be a dominant factor in governing unsaturated soil behavior in addition to $S_{r}$ and $\psi[7]$. Since the compaction $w$-controlled method has been widely used in the construction of earth-fill structures, research on the behavior of material prepared in this way is still ongoing. By using the second method, on the other hand, the effects of different fabrics are eliminated and the effects of $S_{r}$ and $\psi$ can be scientifically investigated while soil fabric and other state parameters remain nearly the same. However, it is more expensive and time consuming and needs more experimental facilities and specialty than the $w$ controlled method. In order to cope with both timeconsuming and costly nature of unsaturated testing, empirical and semi-empirical models (e.g., [8-10]) as well as artificial intelligence method (e.g., [11,12]) were proposed and utilized for predicting unsaturated soil properties. The use of $\psi$-controlled method in research on mechanical behavior of partially saturated soils was pioneered by Hilf in 1956 and it has been followed by others in developing advanced laboratory devices [13]. Despite the large number of studies on the monotonic behavior of unsaturated soils, research on their cyclic and dynamic behavior is still quite limited [14]. One of the main reasons is the limited capability of experimental devices to both control $\psi$ and apply dynamic loading.

Based on $w$-controlled tests conducted by resonant column apparatus (i.e., within small and medium strain ranges), Hardin and Drnevich [15] classified $S_{r}$ in the category of very important parameters affecting dynamic soil properties. It was concluded that although the effect of $S_{r}$ on maximum shear modulus $\left(G_{\max }\right)$ of sand was minor as was confirmed by Tatsuoka et al. [16], different other observations were reported in the experimental work of $\mathrm{Wu}$ et al. [17]. Results of resonant column tests carried out by $\mathrm{Wu}$ et al. [17] on an unsaturated cohesionless soil compacted following $w$ controlled method revealed the significant effect of $S_{r}$ on shear modulus in small strains. It was indicated that $G_{\text {max }}$ had a peak between $S_{r}$ of 5 and $20 \%$ and had an approximately equal value in dry and saturated states. The first small strain tests based on $\psi$-controlled method were most likely reported by Cabarkapa et al. [18] by using bender elements and the direction of this research was picked up by others (e.g., [19$23]$ ). In addition, several $\psi$-controlled resonant column devices were developed and used worldwide to establish $G_{\max }-\psi$ relationships for unsaturated soils (e.g., [23$27]$ ). Results of $\psi$-controlled experiments in most cases revealed that $G_{\max }$ increased to an asymptote by increasing $\psi$ and decreasing $S_{r}$. On the other hand, a clear peak in $G_{\max }$ in the small range of $S_{r}$ 's was measured and reported in the experiments conducted using $w$-controlled technique.

The dynamic properties of soil need to be determined in small and large strains as different ranges of strain are found in different geotechnical problems. Strain levels less than $10^{-5}$ between $10^{-5}$ and $10^{-3}$ and those more than $10^{-3}$ are defined as small, medium, and large strain levels, respectively [28]. Tatsuoka et al. [16] were among the first researchers who investigated the dynamic response of unsaturated sand to cyclic torsional loading. Based on the results of torsional shear tests on the specimens prepared by $w$-controlled method, it was concluded that $G$ and $D$ of sand were not considerably affected by the variations of $S_{r}$ at large strain amplitudes. Similar conclusions were also drawn based on Cyclic Simple Shear (CSS) tests conducted on an unsaturated sand initially compacted to different water contents, while $S_{r}$ varied between 25 and $75 \%$ [29]. On the other hand, the results of $\psi$-controlled triaxial tests demonstrated that the $S_{r}$ variations would affect large strain dynamic parameters [30-32]. A similar conclusion was also drawn based on the experiments conducted using modified CSS devices $[14,33]$. However, the limited results reported the failure to give a clear trend for large strain dynamic properties as a function of $\psi$ in a wide range of potential hydraulic states.

Constrained by the limited scope of experimental data necessary to validate constitutive models, researchers currently have few models at their disposal to predict the behavior of unsaturated soil subjected to dynamic loading. Therefore, the main objective of the current study is to systematically investigate the effects of initial $\psi$ and $S_{r}$ on large strain dynamic properties of unsaturated sand by conducting constant water content dynamic tests using a modified unsaturated CSS apparatus. In order to achieve this goal, sample preparation methods, initial relative densities, saturating processes, vertical net stresses, shear strain amplitudes, and loading frequencies of all samples were considered the same while $\psi$ and $S_{r}$ were the only variables. In this study, the initial $\psi$ was controlled and the initial $S_{r}$ was measured before cyclic shearing to study the effect of these initial parameters on dynamic soil properties. In other words, it is physically impossible to assure constant-suction conditions during cyclic loading because of the relatively fast loading rate. However, variations in both $\psi$ and $S_{r}$ with loading cycles were monitored, to be discussed in the following sections. Hydraulic test conditions were designed such that all zones of Soil Water Retention Curve (SWRC) of Babolsar sand as the test material could be included. Furthermore, discussion about the influence of applying testing method and boundary conditions on 
the observed results is also given. Cyclic test results are interpreted in the context of unsaturated soil mechanics to provide an insight into the influence of hydraulic state on secant shear modulus $(G)$, material damping ratio $(D)$, and cyclic settlement of unsaturated sand.

\section{Experimental procedure}

\subsection{Testing equipment}

The employed CSS apparatus manufactured by Wykeham Farrance Co. is a Swedish Geotechnical Institute (SGI) type. In the SGI type, the soil sample covered by a latex membrane is surrounded by a series of lowfriction thin brass rings. Because of the restriction of soil lateral displacement which is a result of rigidity of the rings, the sample volume change becomes directly proportional to the variations in sample height captured with the external Linear Variable Differential Transformer (LVDT) in the whole testing stages. This device has been used for conducting tests on dry specimens, fully saturated specimens, and unsaturated specimens prepared by $w$-controlled method [29,34]. The CSS apparatus has been further modified recently by incorporating combined water head control and axis translation techniques into it. Therefore $\psi$-controlled tests on unsaturated specimens can be run as well. In fact, the modified unsaturated version can control $\psi$ in the range of zero to $7.5 \mathrm{kPa}$ with a resolution of 0.01 $\mathrm{kPa}$ and in the range of 7.5 to $100 \mathrm{kPa}$ with a resolution of $0.5 \mathrm{kPa}$ by water head control and axis translation techniques, respectively. The above-mentioned range and resolution of $\psi$ control system can precisely cover all zones of SWRC for coarse-grained soils and can provide access to any desired $\psi$ level. Figure 1 shows a schematic of the modified unsaturated CSS apparatus including additional components for controlling suction and measuring saturation degree.

\subsection{Test material}

Babolsar sand collected from the southeast coast of the Caspian Sea was used as the test material. This natural soil has a uniformly graded particle size distribution and is classified as SP (poorly graded sand), according to the Unified Soil Classification System (USCS). In addition, results of index tests conducted following the ASTM standards are given in Table 1.

\subsection{Sample preparation and test procedure}

Prior to testing, the porous ceramic was saturated by imposing vacuum from top cap and consecutive opening/closing of water feeding path beneath the ceramic (Figure 1). A similar saturation process was also followed after preparation of soil specimens using wet tamping method. Dry pluviation and wet tamping are standard laboratory techniques used for preparing sand specimens. However, the latter can give a wider range of relative densities than the former [28]. Therefore, the wet tamping method was adopted by Jafarzadeh and Sadeghi [29] to simulate loose and dense sands in a series of constant-water content cyclic tests. In order to make the comparison possible, testing conditions in this study including sample preparation method were also chosen similarly to the previous work. Accordingly, an amount of oven-dried sand equivalent to $35 \%$ relative density for a cylindrical specimen with



Figure 1. Schematic view of developed $\psi$-controlled cyclic simple shear device (not drawn to scale). 
Table 1. Physical and mechanical properties of Babolsar sand.

\begin{tabular}{|c|c|c|c|}
\hline Physical properties & Symbol & Value & ASTM code \\
\hline Specific gravity & $G_{s}$ & 2.795 & D854-14 \\
\hline Maximum void ratio & $e_{\max }$ & 0.820 & \multirow{2}{*}{ D4254-16 } \\
\hline Minimum dry density $\left(\mathrm{kN} / \mathrm{m}^{3}\right)$ & $\lambda_{d \min }$ & 14.77 & \\
\hline Minimum void ratio & $e_{\min }$ & 0.603 & \multirow{2}{*}{ D4253-16 } \\
\hline Maximum dry density $\left(\mathrm{kN} / \mathrm{m}^{3}\right)$ & $\gamma_{d \max }$ & 16.78 & \\
\hline \multirow{6}{*}{ Particle size distribution } & $D_{10}$ & 0.115 & \multirow{6}{*}{ D6913-17 \& D422-63 \& D2487-11 } \\
\hline & $D_{30}$ & 0.203 & \\
\hline & $D_{50}$ & 0.253 & \\
\hline & $D_{60}$ & 0.273 & \\
\hline & $C_{u}$ & 2.37 & \\
\hline & $C_{c}$ & 1.31 & \\
\hline Mechanical properties & & & Determination \\
\hline$\left(D_{r}=35 \%\right.$ and $\left.\sigma_{v}=50 \mathrm{kPa}\right)$ & & & method \\
\hline Angle of internal friction $\left({ }^{\circ}\right)$ & $\varphi$ & 35 & [63] \\
\hline Coefficient of permeability $(\mathrm{cm} / \mathrm{s})$ & $K$ & 0.015 & [64] \\
\hline Maximum shear modulus (MPa) & $G_{\max }$ & 54 & {$[65]$} \\
\hline
\end{tabular}

$70 \mathrm{~mm}$ diameter and $22 \mathrm{~mm}$ height was weighed. Afterwards, the dry soil was mixed continuously with $5 \%$ gravimetric water content until a uniform mixture was obtained. The mixture was immediately poured into the membrane wrapped over the stacked rings, forming an in-place cylindrical mold. It was thereafter compacted dynamically to reach the final height as close as possible to $22 \mathrm{~mm}$ (controlled and measured using calipers characterized by a precision of $0.01 \mathrm{~mm}$ ). Finally, the cap and the vertical loading frame were assembled.

After sample preparation, the specimen was subjected to $50 \mathrm{kPa}$ vertical stress. When the vertical displacement of sample became almost constant, vacuum was applied to the sample through the path connected to the cap. Afterwards, the bottom path connected to the de-aired water supply through water compartments beneath the ceramic was opened and the soil was saturated step by step. By following a stepwise sequence of opening/closing the water supply valve, entrapped air bubbles were drawn out of the specimen.

Depending on the desired $\psi$, one of the methods of water head control or axis translation was employed. For $\psi$ lower than $7.5 \mathrm{kPa}$, the water head control method was utilized. In this case, pore-air pressure was kept atmospheric and negative pore-water pressure was applied to the specimen. By shifting the adjustable flat board to the desired level below the middle height of the sample, $\psi$ was imposed (Figure 1 ). At $\psi$ higher than $7.5 \mathrm{kPa}$, the axis translation technique was used. While pore-water pressure was kept atmospheric, poreair pressure equal to the desired $\psi$ was imposed. In this technique, vertical stress was increased by applying the pore-air pressure to keep vertical net stress constant.
The same criterion was used for suction equalization using both methods. It was assumed that the soil sample would reach moisture equilibrium once the outflow rate became less than $0.028 \mathrm{ml} / \mathrm{hr}$. This criterion is the best achievable accuracy due to the diameter of the hanging column glass tube (Figure 1), which is better than those in other studies with similar materials (e.g., $[32,33]$ ). However, this outflow rate is equal to the suction variation rates of about $0.005 \mathrm{kPa} / \mathrm{hr}$ and $0.35 \mathrm{kPa} / \mathrm{hr}$ in the transition and residual zones of SWRC of tested material, respectively. The suction variation rates are negligible because the applied suction steps in this study are in the range of about 1 to $10-60 \mathrm{kPa}$ in the transition and residual zones, respectively.

Three test stages including compression, saturation, and suction equalization were proceeded, respectively. In all these stages, the variations in relative density were monitored until achieving both mechanical and hydraulic equilibria. At the end of the suction equalization stage or before starting the cyclic shearing, the relative density was increased by $10 \%$ to $45 \%$, on average. Indeed, a $10 \%$ rise in relative density compared to the after-compaction value arose from application of net stress, saturation, and suction. Following the moisture equilibrium, strain-controlled CSS was applied to the specimens and the variations in shear stress and vertical displacements were recorded by the control and data acquisition system of the device.

\section{Dynamic testing program}

Based on the applied shear strain amplitude, dynamic tests can be divided into two categories of 
non-destructive and destructive tests, separated by a strain amplitude called threshold strain. Because $\psi$ controlled experiments can be time consuming, this classification tends to become important in research regarding partially saturated soils. In non-destructive tests corresponding to the small range of strains, a single specimen can be used under a variety of hydraulic conditions (e.g., [35]). Conversely, running multistage tests on a sample subjected to large destructive prestrains in the first stage may not be scientifically acceptable because of the significant changes in soil structure and state [36,37]. Hence, a new similar specimen should be prepared and sheared in large strains for each desired hydraulic state. However, the time-consuming and costly nature of $\psi$-controlled experiments was the main reason for selecting the multistage testing protocol by several research groups (e.g., [38]). As an example, Biglari et al. [31] conducted a series of multistage cyclic triaxial tests on unsaturated clay samples by increasing deviatoric stress in three loading steps. Although the multistage testing provides more information than the single-stage testing, it has a major limitation when destructive tests are required due to substantial changes in soil fabric and state after each stage [39]. Since the proposed testing in the current research is cyclic shearing at a large strain amplitude, which is considered destructive, the singlestage testing protocol was chosen at all $\psi$ levels.

Previous studies have mostly focused on the effects of shear strain amplitude, effective mean confining stress, void ratio, and number of cycles $(N)$ as the effect of these factors on $G$ and $D$ of sand remains very important [15]. Since the hydraulic state of a soil element before testing has not received enough attention, the aim of the current research is exclusively to evaluate the effects of initial $\psi$ and $S_{r}$ on dynamic properties of unsaturated sand. Therefore, apart from the aforementioned two variables, the rest of influencing factors were considered essentially the same for all the tests conducted. Consequently, test conditions such as loading shape (i.e., sinusoidal), vertical net stress (i.e., $50 \mathrm{kPa}$ ), relative density before shearing (i.e., $45 \%$ ), and shear strain amplitude (i.e., $1 \%$ ) were chosen similar to the previously published results of this group [29] for the sake of comparison. Of note, the initial relative density of test specimens was selected such that the resulting value before cyclic shearing could be laid within the range of relative densities considered by Jafarzadeh and Sadeghi [29]. As a result, a comparable trend would be expected if initial suctioncontrol conditions were similar to the compaction water content-control conditions. The validity of this assumption will be investigated and discussed later. Another objective of this study is to compare dynamic results of $w$-controlled and $\psi$-controlled tests. There will be more discussions on the selection of applied $\psi$, drainage condition, and loading frequency, which are explained in the following subsections.

\subsection{Applied suctions}

A new approach to selecting $\psi$ of tests was adopted in which the imposed $\psi$ values were chosen according to the measured SWRC of test material. Correspondingly, the first step is to determine the SWRC of Babolsar sand under the same conditions as the main dynamic tests. Figure 2 shows the results of SWRC test as well as the best curves of three SWRC models fitting to the data points. Brooks and Corey [40], Van Genuchten [41], and Fredlund and Xing [42] models were selected and they included one " $\lambda$ ", two " $a$ and $n$ ", and three " $a, n$, and $m$ " fitting parameters, respectively. The curve fitting parameters are given in Table 2. In this case, the prediction accuracy of the models does not necessarily improve upon an increase in the number of parameters; however, additional parameters simply increase the curvature. Based on the method proposed by Vanapalli et al. [43], the Air Entry Value (AEV) and the Residual Value (RV) were determined as 2.4 and $5.1 \mathrm{kPa}$, respectively. Therefore, the boundaries of Capillary Zone (CZ), Transition Zone (TZ), and Residual Zone (RZ) were well defined. Finally, $\psi$ values were selected based

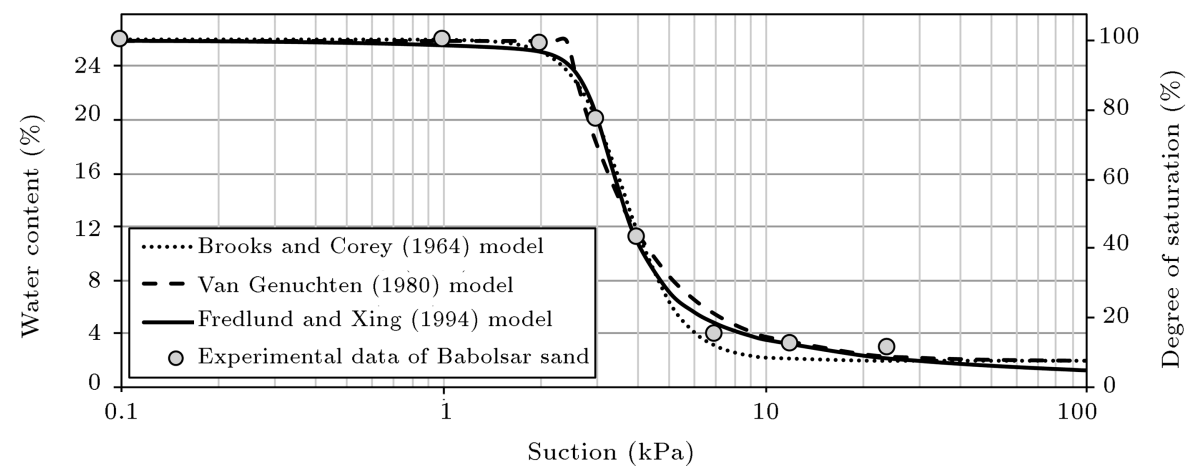

Figure 2. Best fits of three models to measured Soil Water Retention Curve (SWRC) data points, $44 \%$ relative density, and $50 \mathrm{kPa}$ net vertical stress (see Table 2). 
Table 2. Curve fitting parameters of Soil Water Retention Curve (SWRC) models (see Figure 2).

\begin{tabular}{lcccccc}
\hline \multicolumn{1}{c}{ Model } & $\begin{array}{c}\text { Brooks and } \\
\text { Corey (1964) }\end{array}$ & $\begin{array}{c}\text { Van Genuchten } \\
\mathbf{( 1 9 8 0 )}\end{array}$ & \multicolumn{2}{c}{$\begin{array}{c}\text { Fredlund and } \\
\text { Xing (1994) }\end{array}$} \\
\hline Reference no. & {$[40]$} & \multicolumn{2}{c}{$[41]$} & & {$[42]$} & \\
Parameter & $\lambda$ & $a$ & $n$ & $a$ & $n$ & $m$ \\
Value & 1.808 & 0.287 & 5.415 & 0.781 & 9.354 & 2.994 \\
$\boldsymbol{R}^{\mathbf{2}}$ & 0.9920 & \multicolumn{2}{c}{0.9984} & & 0.9982 & \\
\hline
\end{tabular}

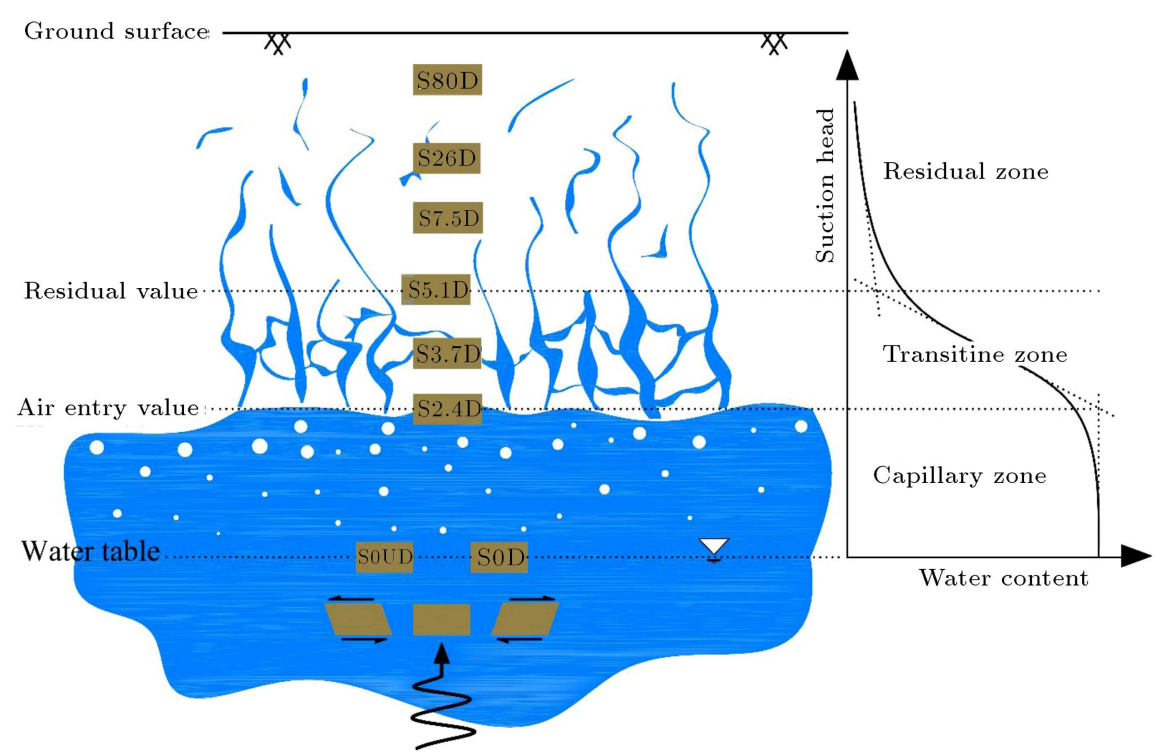

Figure 3. The analogy between test specimen conditions from the hydraulic viewpoint and the field conditions of soil elements above the ground water table.

on these characterized zones to take into account all critically important hydraulic conditions as follows:

1. Zero $\psi$ (the first point of $\mathrm{CZ}$ );

2. $\mathrm{AEV}$ (the boundary between $\mathrm{CZ}$ and $\mathrm{TZ}$ );

3. Inflection point of SWRC (a point in the middle of TZ);

4. RV (the boundary between $\mathrm{TZ}$ and RZ);

5. Three consecutive points within RZ (Figure 3).

\subsection{Drainage conditions}

The drainage conditions of fully saturated samples in laboratory element testing are controlled by opening/closing the pore-water valves connected to the top or bottom of the samples [44]. However, in $\psi$ controlled experiments, drainage conditions are contingent upon the pore-air and pore-water phases, which are normally controlled through top cap and modified bottom pedestal, respectively [45]. In natural unsaturated soil layers, air phase is continuous after the AEV. Although the coefficient of air permeability is reduced upon increase in $S_{r}$, the air permeability values become significantly large when air phase is continuous [3]. Therefore, drained conditions can be assumed for pore-air pressure under quick loading after AEV. Accordingly, the cyclic shearing stage of all the tests in the present study, except the saturated one (i.e., zero $\psi$ ), was carried out under drained pore-air conditions by keeping open the path connected to the top cap to atmospheric pressure or air pressure supply using water head control method or axis translation technique, respectively. Additionally, the tests were carried out in undrained pore-water conditions by closing the drainage valve connected to the volume change measurement (WVC) in Figure 1. Hence, cyclic tests were conducted in a constant water content condition.

Regarding fully saturated soils, there has been a general unanimity that the behavior of saturated sand below the ground water level under simulated earthquake loading is almost undrained (e.g., [29,46]). However, the drainage conditions just above the groundwater table are more complicated and still unknown. For example, a soil element can be assumed at the groundwater table in the sand stratum (soil element SOUD or S0D in Figure 3) where $\psi$ is zero, but pore water has a chance to quickly find its flow path to the unsaturated zone. In order to examine the extreme response of this soil element to dynamic loading under 
Table 3. Summary of dynamic testing program and testing conditions.

\begin{tabular}{|c|c|c|}
\hline Sample preparation method & \multicolumn{2}{|c|}{ Moist tamping } \\
\hline Initial water content of compaction & \multicolumn{2}{|l|}{$5 \%$} \\
\hline Initial relative density after compaction & \multicolumn{2}{|l|}{$35 \%$} \\
\hline Net vertical stress & \multicolumn{2}{|c|}{$50 \mathrm{kPa}$} \\
\hline Cyclic loading control mode & \multicolumn{2}{|c|}{ Strain-controlled } \\
\hline Cyclic loading shape & \multicolumn{2}{|c|}{ Sinusoidal } \\
\hline Shear strain amplitude & \multicolumn{2}{|l|}{$1 \%$} \\
\hline Cyclic loading frequency & \multicolumn{2}{|c|}{$1 \mathrm{~Hz}$} \\
\hline Number of cyclic loading & \multicolumn{2}{|l|}{50} \\
\hline \multirow{7}{*}{ Initial suction $(\mathrm{kPa})$} & 0 & First point of $\mathrm{CZ}$ \\
\hline & 2.4 & $\mathrm{AEV}$ \\
\hline & 3.7 & Midpoint of TZ \\
\hline & 5.1 & $\mathrm{RV}$ \\
\hline & 7.5 & First point within RZ \\
\hline & 26 & Second point within $\mathrm{RZ}$ \\
\hline & 80 & Third point within RZ \\
\hline Hydraulic path & \multicolumn{2}{|c|}{ Main drying } \\
\hline
\end{tabular}

possible drainage conditions, two tests were performed at zero $\psi$ under completely undrained (SOUD) and drained conditions (SOD).

\subsection{Cyclic loading frequency}

The cyclic loading frequency of dynamic tests to determine the modulus and damping properties of soils has been restricted by ASTM D3999 [44] to the range of 0.1 to $2 \mathrm{~Hz}$. However, cyclic loading frequencies as low as almost 0.00005 to $0.000007 \mathrm{~Hz}$ and $0.002 \mathrm{~Hz}$ were respectively chosen by Biglari et al. [31] and Milatz and Grabe [14] for their studies at large-strain under the $\psi$ controlled conditions. Selection of such low frequencies by Biglari et al. [31] was to ensure that no excess pore water and pore-air pressure would be generated during shearing stage so that the assumption of constant suction could be valid. Milatz and Grabe [14] selected low frequency to provide enough time for the embedded tensiometer to respond to changes of suction during shearing. It is also noted that real-time control of $\psi$ at high loading frequencies may not be possible since the response time of pore water to any hydro-mechanical changes is very short, because the permeability of water phase is significantly reduced by $\psi$ in unsaturated soils. In addition, the permeability of high air-entry value of ceramic disk is too low to achieve pressure balance quickly [13]. Although $\psi$ can be better controlled or measured at low frequencies, the dynamic response is affected as well because of the rate (or frequency) dependent behavior of soils [47]. Therefore, all specimens were brought to a specific initial $\psi$-controlled condition and sheared afterwards with a loading frequency of $1 \mathrm{~Hz}$ in accordance with
ASTM D3999 [44] to remove the frequency effects and to examine the influence of initial hydraulic conditions on subsequent dynamic properties in a more realistic loading scenario. Finally, the detailed experimental program is given in Table 3 .

\section{Experimental results}

The details of test conditions after moisture equalization and before cyclic shearing are summarized in Table 4. The void ratio was calculated based on cumulative sample settlements during compression, saturation, and moisture equalization stages. The values of void ratio show that $\psi$ level has not significantly influenced the volumetric behavior of sand during moisture equalization. The error column indicates the difference between the measured water content after the test and the calculated water content based on mass-volume relationships and the total water exchange during moisture equalization. The error justifies the high quality of conducted tests as well as the reliability of controlling and measuring units since it is limited to maximum $4.7 \%$ and is $3 \%$ on average for all the tests conducted.

\subsection{Reproducibility of results}

In the current study, several specimens were compacted, saturated, compressed, desaturated at different levels of $\psi$, and eventually sheared. Controlling repeatability of tests and reproducibility of results is one way to guarantee the similarity between specimens of the main tests and to make sure that results are reliable for comparison and interpretation, as can be 
Table 4. Sample conditions before cyclic shearing stage.

\begin{tabular}{ccccccc}
\hline & \multicolumn{5}{c}{ Parameter } \\
\cline { 2 - 7 } Test ID & $\begin{array}{c}\text { Drainage } \\
\text { condition }\end{array}$ & $\begin{array}{c}\text { Void } \\
\text { ratio }\end{array}$ & $\begin{array}{c}\text { Water } \\
\text { content }\end{array}$ & Error & $\begin{array}{c}\text { Degree of } \\
\text { saturation }\end{array}$ & Suction \\
\cline { 3 - 7 } & $\boldsymbol{e}$ & $\boldsymbol{w}(\boldsymbol{\%})$ & $(\boldsymbol{\%})$ & $\boldsymbol{S}_{\boldsymbol{r}}(\boldsymbol{\%})$ & $\boldsymbol{\psi}(\mathbf{k P a})$ \\
\hline S0UD & Undrained & 0.723 & 25.4 & - & 100 & 0 \\
S0D & & 0.723 & 25.4 & - & 100 & 0 \\
S2.4D & & 0.726 & 24.1 & 0.1 & 92.9 & 2.4 \\
S3.7D & & 0.719 & 12.8 & 4.6 & 49.7 & 3.7 \\
S5.1D & Drained & 0.728 & 5.3 & 4.7 & 20.2 & 5.1 \\
S7.5D & & 0.728 & 3.5 & 2.9 & 13.3 & 7.5 \\
S26D & & 0.726 & 2.2 & 3.3 & 8.8 & 26 \\
S80D & & 0.717 & 1.7 & 2.7 & 6.6 & 80 \\
\hline
\end{tabular}



(a)



(b)

Figure 4. Repeatability of test results in terms of hydraulic behavior: (a) Water outflow during $\psi$ equalization and (b) Soil Water Retention Curve (SWRC).

reproduced by others. Four additional tests were therefore conducted with conditions similar to the tests S0D, S2.4D, S5.1D, and S7.5D to evaluate the repeatability. This evaluation can be carried out in hydraulic and mechanical terms in experimental unsaturated soil testing. From the hydraulic viewpoint, transient flow behavior during moisture equalization and SWRC being the ultimate objective are presented in Figure 4 as the main hydraulic characteristics of unsaturated soil. Figure 4(a) shows that both the equilibrium time and total volume of outflow water are in very good agreement for all the six tests compared to each other. Results of SWRC plotted in terms of $\psi$ against $S_{r}$ (Figure 4(b)) also indicate a very good match between three groups of independent tests on different specimens, confirming the reliability of controlling and measuring suction and saturation degree, respectively. In terms of mechanical behavior, on the other hand, shear stress-strain curves of the main and repeated tests are plotted in Figure 5 for the first ten cycles. Nonlinear response of soil to dynamic loading in large strain results in hysteresis behavior. This tilde shape of stress-strain curves was reported in large strain cyclic shearing tests on sand under drained conditions in the literature (e.g., $[37,48]$ ). The curves of the main and repeated experiments of tests S0D, S5.1D, and S7.5D are in reasonable agreement. Although the curves of the main and repeated tests $\mathrm{S} 2.4 \mathrm{D}$ do not exactly match, the overall trends in terms of average slope and the hysteresis loop area having a direct influence on $G$ and $D$ are still close and comparable, respectively.

\subsection{Shear modulus and damping ratio}

The cyclic stress-strain curve can be characterized by two parameters of secant modulus $(G)$ and damping ratio $(D) . \quad G$ and $D$ in each cycle are determined through hysteresis loops (e.g., Figure 5). The loop of a typical cycle is plotted in Figure 6 and the calculation procedure for shear modulus $(G)$ and material damping ratio $(D)$ is given. It is noted that in all straincontrolled experiments conducted in current research, the difference between strains (i.e., denominator) was constant and equal to 0.02 . Figure 7 shows variations in $G$ and $D$ with $N$ for unsaturated Babolsar sand dried to different values of $\psi$. At all $\psi$ values except zero, $G$ increases and $D$ decreases to asymptotic levels with $N$. Although these asymptotic levels are dependent on $\psi$, similar trends for variations in both $G$ and $D$ against $N$ can be observed independent of $\psi$. It can, therefore, be concluded that $\psi$ does not seem to have a notable 


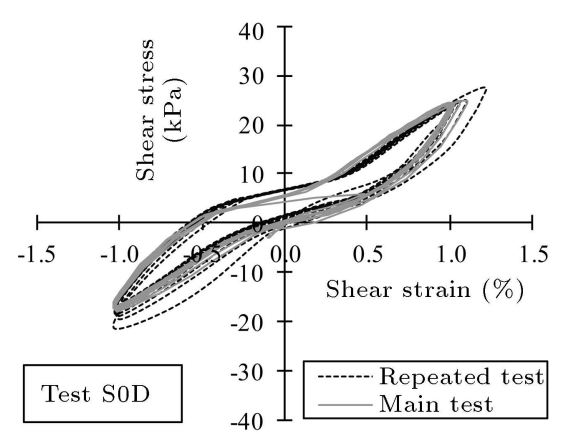

(a)



(c)

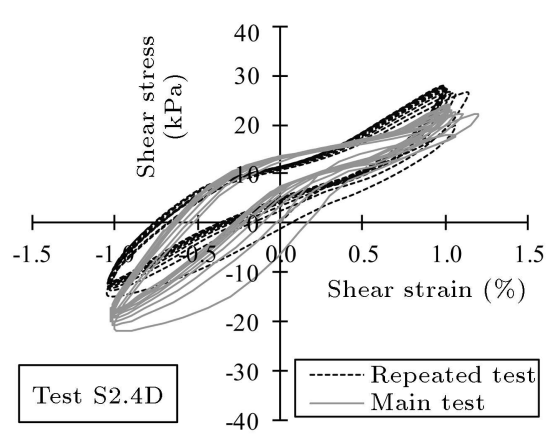

(b)

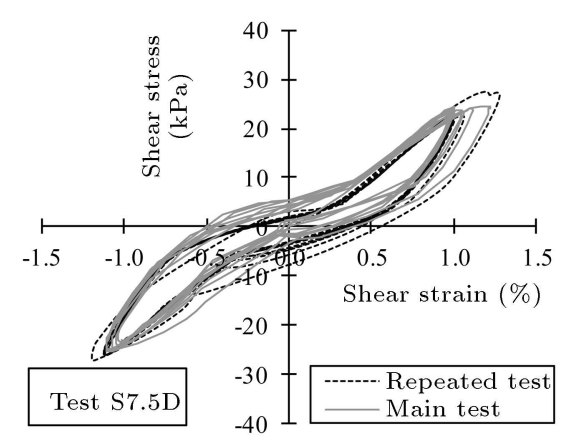

(d)

Figure 5. Repeatability of test results in terms of cyclic behavior (the first ten cycles): (a) Test S0D, (b) Test S2.4D, (c) Test S5.1D, and (d) Test S7.5D.

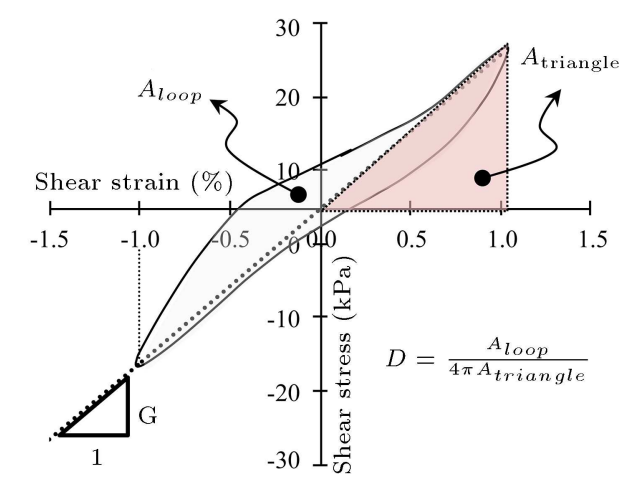

Figure 6. Calculation procedure of $G$ and $D$ from a typical strain-stress loop.

influence on the way $G$ and $D$ vary with $N$. The analysis of results and a more in-depth interpretation of measured dynamic properties will be discussed in the next section.

\subsection{Cyclic volumetric change behavior}

The plastic strain at the end of each cycle results in a new void ratio. The changes in the void ratio in each cycle $\left(\Delta e=e_{N}-e_{N-1}\right)$ versus $N$ are plotted in Figure 8. At first glance, the variations in $\Delta e$ against the number of cycles seem to be very similar for all suctions. However, a closer look at Figure 8 reveals that there are differences in volumetric changes at different suction levels. If the maximum distances between two adjacent cycles are considered, i.e., the two sets of data points plotted in solid grey in Figure 8,

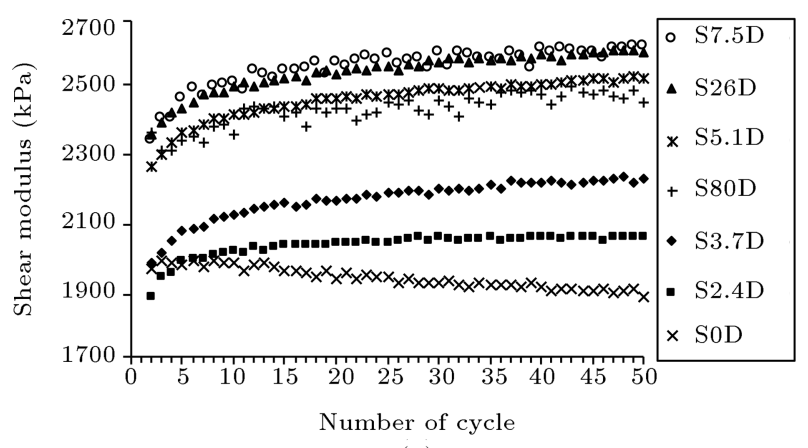

(a)



(b)

Figure 7. Variations in dynamic properties of drained tests with the number of cycles: (a) $G$ versus $N$ and (b) $D$ versus $N$.

the maximum fluctuation in $\Delta e$ is obtained. These comparisons reveal that variations in $\Delta e$ can be as high as almost $60 \%$ for the two adjacent points colored 




Figure 8. Volumetric variations during cyclic shear loading.

in solid grey. Although this amount of error in percentage is relatively significant, it should be taken into consideration that quantified error is bound to 0.00008 in terms of void ratio. As a result, the error included in measuring settlement or void ratio is well within the allowable experimental error of $5 \%$. Such small variations could be related to some sources of external noise. Nevertheless, further technological achievements are required to get more accurate measurements. However, according to the results in Figure $8, \Delta e$ is generally the highest and lowest for the specimens in the fully saturated state (SOD) and in a relatively dry state $(\mathrm{S} 80 \mathrm{D})$, respectively. In other words, results suggest that $\Delta e$ decreases due to a rise in suction. These observations confirm the stiffening effects of suction on intergranular forces, hence being a resisting agent against the enhancement of cyclic settlement. Although the effect of suction on cyclic volumetric behavior is clear, it should be noted that the overall volumetric differences are very marginal, as reflected in the magnitude of $\Delta e$.

\section{Interpretation of test results}

\subsection{Effects of initial suction}

The effects of initial $\psi$ on $G$ and $D$ in the two cycles (5th and the last cycles) are shown in Figure 9(a) and (b), respectively. The average values of all 50 cycles are also superimposed for comparison. According to Figure 9(a), there are slight changes in $G$ upon increase in $\psi$ from zero to $\mathrm{AEV}$. In $\mathrm{CZ}$, negative porewater pressure can only marginally increase the mean effective stress. In fact, the variations in $\psi$ and mean effective stress are equal in this zone since the soil is still saturated. After AEV, as $\psi$ increases, the amount of air in soil pores increases significantly. Therefore, the soil response changes progressively from bulkwater to menisci-water regulated behavior [24]. In TZ, i.e., between AEV and RV, meniscus connections become thinner as $\psi$ grows. Hence, the tension stresses between adjacent particles and thus, mean effective stress of



(a)

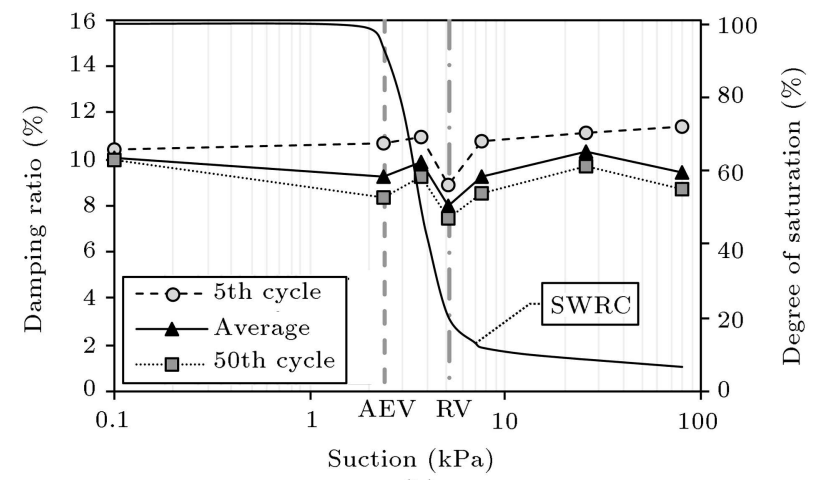

(b)

Figure 9. Dynamic properties of unsaturated sand in different hydraulic states corresponding to all zones of Soil Water Retention Curve (SWRC): (a) $G$ versus $\psi$ and (b) $D$ versus $\psi$ (AEV: Air Entry Value; RV: Residual Value).

soil increase [49]. In addition, according to SWRC, $S_{r}$ suddenly decreases and consequently, lubrication between sand grains is reduced significantly. As a result, the combination effects of suction stress [50] and boundary lubrication [51] in this zone result in a sharp rise in $G$. Biglari et al. [31] also reported this dramatic rise in $G$ following the enhancement of $\psi$ in TZ. In RZ, on the one hand, further increase in $\psi$ increases the tension between particles and some thin meniscus connections disappear, on the other hand [52]. Therefore, the suction stress in sand decreases in this zone [50]. Furthermore, due to the slight variations observed in $S_{r}$ in this zone, the effects of lubrication between sand grains on $G$ are not enormous. Therefore, the result of the aforementioned counteracting factors causes $G$ to decline with further increase in $\psi$ within RZ. In conclusion, $G$ of the unsaturated sand in large strains was shown to be affected by both suction stress and inter-particle lubrication. The former is characterized by negative pore-water pressure in $\mathrm{CZ}$, tension stress among meniscus connections in $\mathrm{TZ}$, and numbers of meniscus connections in RZ. The latter, on the other hand, had insignificant effects on $\mathrm{CZ}$ and $\mathrm{RZ}$ and significant effect on TZ. It is noticeable that in strains less than threshold level where particles do not move, the only influencing parameter is suction stress. 
Compared to $G$, the investigation of the energy damping mechanism in geomaterial has received insignificant attention [53]. The friction between particles, strain rate effect, and nonlinear behavior of soil are the mechanisms that affect $D$ [54]. In addition, damping mechanism takes place on sliding between loaded particles. In unsaturated soil, two mechanisms are evident. The first mechanism is the variations in $S_{r}$, influencing the friction and sliding amongst particles. The second one is the variations in $\psi$ and $S_{r}$, leading to changes in suction stress, and soil nonlinear behavior and stored strain energy would change as a result. The trend of $D$ against $\psi$ can be interpreted by making use of the aforementioned mechanisms. Figure 9(b) demonstrates that variations in $D$ with $\psi$ are not considerable in CZ because the variations in $\psi$ and $S_{r}$ are negligible in this zone. However, $D$ reaches the minimum value of all the examined suctions at RV and increases afterwards. In TZ, the two mentioned mechanisms cause a slight increase in $D$ followed by a reduction. However, in RZ, while $S_{r}$ does not change considerably, water bridges between particles gradually disappear. Therefore, the increase in energy attenuation in RZ can be attributed to the gradual disappearance of meniscus connections and nearly constant stiffness. Experimental studies of the effects of $\psi$ on $D$ of unsaturated sand are quite limited. Nonetheless, Biglari et al. [31] and Hoyos et al. [23] reported a decreasing trend for $D$ with $\psi$, being consistent with the results of variations in $D$ within TZ. In fact, the range of $\psi$ considered in their studies was only limited to $\mathrm{TZ}$ of the corresponding SWRCs of a lean clay [31] and a silty sand [23].

The trend of variations in shear modulus versus some parameters such as the shear strain amplitude, confining pressure, void ratio, and plasticity index has been massively studied and reported in the literature. However, such a comparison has not been made yet for the variations in shear modulus versus suction normalized to saturated modulus and the AEV, respectively. Figure 10 indicates the comparison between the $G / G_{\text {sat }}$ and $\psi / \mathrm{AEV}$ variations derived from different experimental reports, also summarized in Table 5 . Although there is a wide range of variations in $G / G_{\text {sat }}$ against the normalized suction for the reported dataset, consistent suction-induced stiffening can be found for all the test series. It is important to note that there are differences between the results of different research groups for similar soil types and strain amplitudes. For example, the observed discrepancies shown in Figure 10 among the results of $\mathrm{Ng}$ et al. [21], Khosravi and McCartney [55], Ghayoomi et al. [32], and the current study cannot be simply neglected. However, as will be discussed in the following section in more detail,



Figure 10. Comparison between results of this study and those reported in the literature in terms of $G / G_{\text {sat }}$ versus $\psi /$ AEV (see Table 5).

Table 5. Testing conditions for the experimental results of Figure 10.

\begin{tabular}{lccccc}
\hline \multicolumn{1}{c}{ Study } & $\begin{array}{c}\text { Soil } \\
\text { type } \\
\text { (USCS) }\end{array}$ & $\begin{array}{c}\text { Strain } \\
\text { range }\end{array}$ & Device & $\begin{array}{c}\text { Sample } \\
\text { preparation } \\
\text { method }\end{array}$ & $\begin{array}{c}\text { Reference } \\
\text { no. }\end{array}$ \\
\hline Mancuso et al. (2002) & CL & Small strain & RC & Dynamic compaction & {$[24]$} \\
Ng et al. (2009) & ML & Small strain & BE & Dynamic compaction & {$[21]$} \\
Khosravi et al. (2010) & SP & Small strain & RC & Dry pluviation & {$[26]$} \\
Khosravi and McCartney (2012) & ML & Small strain & RC & Static compaction & {$[55]$} \\
Ghayoomi et al. (2017) & SP & Large strain & CT & Dry pluviation & {$[32]$} \\
Le and Ghayoomi (2017) & SP & Medium strain & CSS & Dry pluviation & {$[33]$} \\
\hline
\end{tabular}

Note: RC: Resonant Column, BE: Bender Element, CT: Cyclic Triaxial, and CSS: Cyclic Simple Shear. 
not only soil type and strain range but also other influencing parameters such as stress state, stress path, and sample preparation method play important roles in governing the dynamic soil behavior. Despite some discrepancies between experimental data, results of Figure 10 suggest that most of the data follow an Sshaped trend, yet with different magnitudes. This type of sigmoid trend for variations in normalized stiffness versus normalized suction has been introduced and compared in a relatively wide range of unsaturated soils for the first time. It is interesting that the general trends of G- $\psi$ already discussed for different SWRC zones can be somehow observed for other series of experimental results reported in the literature.

\subsection{Effects of initial degree of saturation}

Variations in $G$ and $D$ with $S_{r}$ for three cycles are shown in Figure 11(a) and (b), respectively. Although the abscissa covers a wide range of $S_{r}$ from nearly 7 to $100 \%$, reaching lower $S_{r}$ values requires applying very high air pressure to the specimen. In other words, it is very difficult and time consuming to force water out of an unsaturated specimen after RV. Based on experimental results and theoretical thermodynamic considerations, it has been proved that $\psi$ corresponding to zero $S_{r}$ is about one million $\mathrm{kPa}$ and is the same for all types of soil [42]. As a result, the study of dynamic behavior of soils by means of axis translation technique

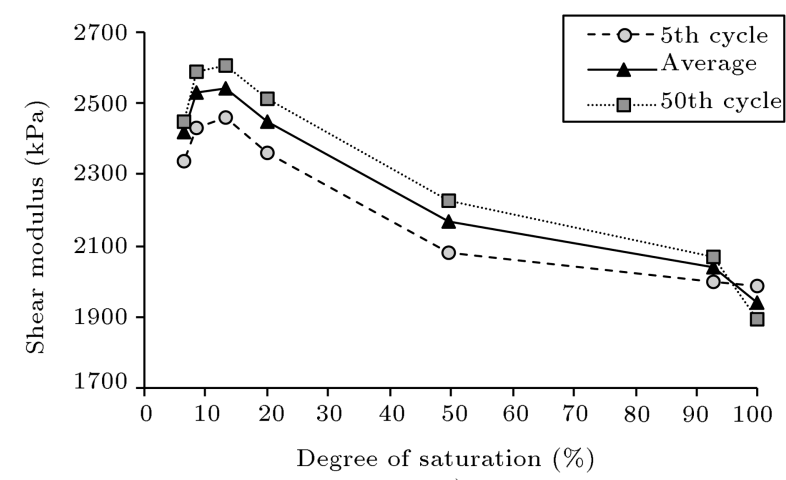

(a)



(b)

Figure 11. Variations in dynamic properties with $S_{r}$ in various cycles: (a) $G$ and (b) $D$. is impractical at very low $S_{r}$, and other methods such as vapor equilibrium technique should be incorporated into the apparatus design.

According to Figure 11(a), $G$ increases at the starting degree of saturation by as low as $7 \%$ to a peak laying between $10 \%$ and $20 \% S_{r}$. Similar trends were reported by $\mathrm{Wu}$ et al. [17] who measured the peak at the stiffness ratio $\left(G / G_{\text {dry }}\right)$ of unsaturated sand at low degrees of saturation between $5 \%$ and $20 \%$. They called the corresponding degree of saturation to the peak stiffness ratio as "the optimum degree of saturation." When the peak takes place, there will be a continuous decrease in shear modulus in proportion to the degree of saturation until it approaches $90 \%$. The experimental measurements follow a trend that is very similar to the negative exponential function in this wide range of $S_{r}$ 's. Afterwards, the rate of decrease in shear modulus accelerates and there is a sharp descent in $G$, while $S_{r}$ varies from $90 \%$ to $100 \%$. A possible reason for this significant reduction in $G$ at high degrees of saturation is the partial generation of excess pore water pressure contributing to shear resistance and shear modulus. A similar conclusion was also drawn by those studies that had investigated the liquefaction resistance of partially saturated sand at degrees of saturation more than $98 \%$ (e.g., [56,57]).

Figure 11(b) indicates the variations in $D$ at the degree of saturation ranging from $7 \%$ to $100 \%$. Compared to shear modulus, $D$ is much less influenced by the variations in degree of saturation as the maximum change in damping ratio is limited to $2 \%$ for a wide range of $S_{r}$ 's. Of particular interest is the occurrence of a valley in $D$ at a saturation degree slightly higher than the optimum degree of saturation where the stiffness becomes maximum. In other words, the minimum $D$ corresponds to the $20 \%$ degree of saturation, while the peak stiffness is measured at $S_{r}$ value of $15 \%$. Therefore, the interesting finding is that the maximum shear modulus and the minimum damping ratio do not occur at the same degree of saturation. This is a new experimental proof that in addition to the shear modulus being inversely proportional to $D$, other mechanisms like lubrication make a notable contribution to damping characteristics. As the degree of saturation increases, inter-particle lubrication tends to facilitate slippage and relative displacement between sand particles under cyclic loading. This mechanism, in fact, implies that water lubrication should result in a rise in damping. These two opposite contributors, i.e., stiffness and lubrication, result in the occurrence of minimum damping at a degree of saturation higher than that corresponding to the maximum $G$. Afterwards, the two counteracting phenomena almost neutralize each other, resulting in a marginal influence of degree of saturation on $D$, while $S_{r}$ ranges from $20 \%$ to $100 \%$. 
Table 6. Testing conditions for the experimental results of Figure 12.

\begin{tabular}{lccccc}
\hline \multicolumn{1}{c}{ Study } & $\begin{array}{c}\text { Soil } \\
\text { type } \\
\text { (USCS) }\end{array}$ & $\begin{array}{c}\text { Strain } \\
\text { range }\end{array}$ & Device & $\begin{array}{c}\text { Sample } \\
\text { preparation } \\
\text { method }\end{array}$ & $\begin{array}{c}\text { Reference } \\
\text { no. }\end{array}$ \\
\hline Wu et al. (1984) & SP & Small strain & RC & Dynamic compaction & {$[17]$} \\
Khosravi et al. (2010) & SP & Small strain & RC & Dry pluviation & {$[26]$} \\
Ghayoomi et al. (2017) & SP & Large strain & CT & Dry pluviation & {$[32]$} \\
Le and Ghayoomi $(2017)$ & SP & Medium strain & CSS & Dry pluviation & {$[33]$} \\
\hline
\end{tabular}

Note: RC: Resonant Column, CT: Cyclic Triaxial, and CSS: Cyclic Simple Shear.

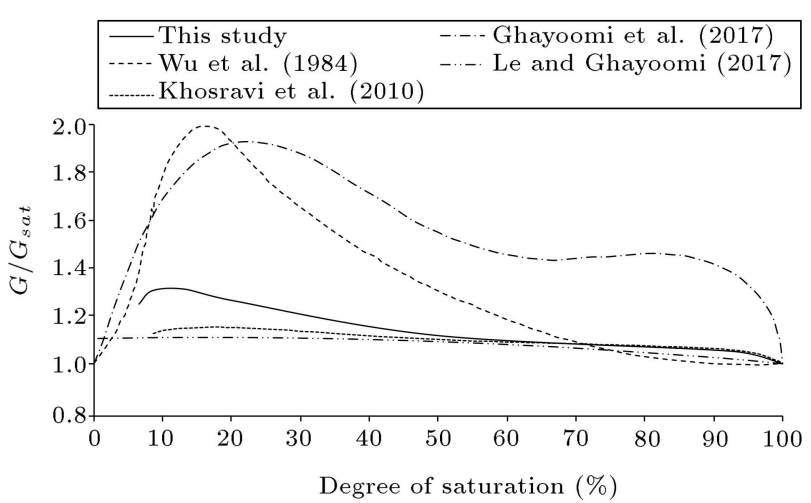

Figure 12. Comparison between results of this study and those reported in the literature in terms of $G / G_{\text {sat }}$ versus $S_{r}$ (see Table 6).

Results in terms of normalized shear modulus $\left(G / G_{\text {sat }}\right)$ versus degree of saturation are compared with the experimental measurements of previous research on sand in Figure 12. Detailed information on soil type and strain range employed in each study is provided in Table 6. According to the results, a peak at the stiffness ratio between $S_{r}$ values of $10 \%$ to $25 \%$ was measured and reported by all studies except the study of Le and Ghayoomi [33] who did not observe significant $S_{r}$ influence on stiffness ratio. However, the peak values varied considerably from 1.3 to 2.0 in different experimental reports. The observed trends shown in Figure 12 could be divided into two parts being delimited at the degree of saturation of about $70 \%$. At saturation degrees higher than $70 \%$, insignificant variation in $G / G_{\text {sat }}$ can be observed for all the previously published data, except the study of Ghayoomi et al. [32]. On the other hand, the peak value of $G / G_{\text {sat }}$ was reached at saturation degrees lower than $70 \%$ for all the reported data series, except the results of Le and Ghayoomi [33]. In other words, other experimental studies, except the two recent works, generally reveal the significant influence of $S_{r}$ on $G / G_{\text {sat }}$ at saturation degrees lower than $70 \%$, while this influence is negligible for higher values. A possible reason why no significant changes occurred to the shear modulus at saturation degrees higher than $70 \%$ is that soil conditions approach nearly saturated states and hence, suction magnitudes are relatively small. As a result, the contribution of suction and saturation degree to shear modulus is relatively insignificant compared to the conditions where the saturation degrees are lower than $70 \%$. In the lower range, indeed, suction is enhanced significantly and strong tensile menisci are formed between soil particles, which in turn result in the augmentation of stiffness. Therefore, the peak shear modulus occurred in this range followed by a steep reduction in shear modulus with the further enhancement of suction as the menisci start vanishing due to the lack of water.

One possible explanation for the observed discrepancies is the difference in soil types, testing strain range, stress path (testing device type), and sample preparation method [7,24]. Testing conditions for results of Figure 12 are detailed in Table 6 . An increase in the strain amplitude can notably suppress the effects of confining stress, void ratio, plasticity index, and other influential parameters such as suction or saturation degree on shear modulus [58]. In Table 6, different strain amplitudes were used in reported studies, which could yield different outcomes. Furthermore, differences in the stress states applied in various testing devices could lead to different results [59]. Accordingly, in addition to $S_{r}$, there are a number of other factors such as testing conditions in Table 6 at play. To reduce the effects of other parameters and to put the focus on the influence of $S_{r}$, shear modulus was normalized to the saturated state. However, the effects of other companions may not be simply neglected. As a result, it can only be concluded from results of Figure 12 that the initial hydraulic condition is a key factor dominating the trends of variations in $G$ versus $S_{r}$. Such a conclusion might not be drawn based on the previous study [29] that was subject to the device limitation in controlling or measuring the initial soil suction.

\subsection{Effects of testing method}

The experimental conditions and the device used in this study were purposely selected, similar to the previous study conducted by Jafarzadeh and Sadeghi [29], for a fair comparison between the effectiveness rates of testing methods. Therefore, the main difference be- 


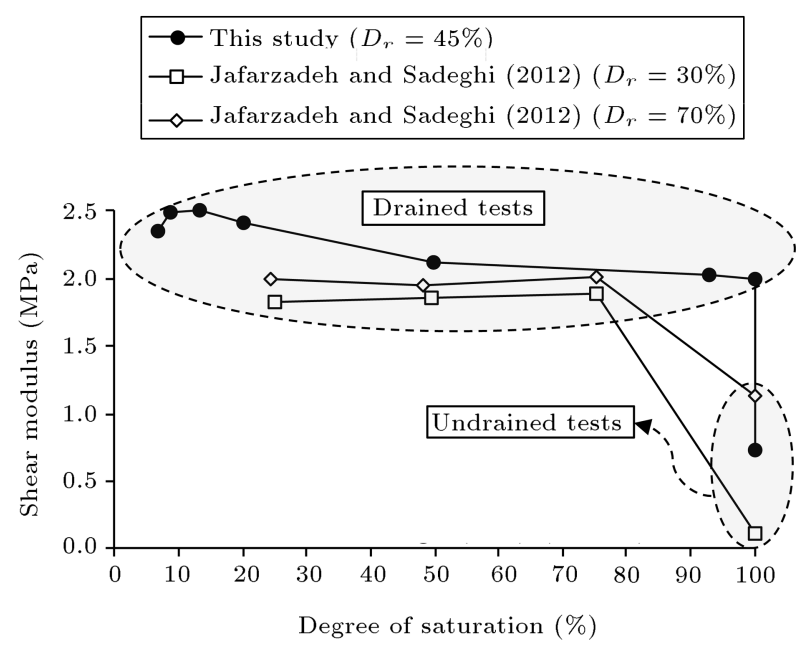

Figure 13. Comparison between results of $\psi$-controlled and $w$-controlled tests in terms of $G$ versus $S_{r}$ (Babolsar sand, vertical net stress $50 \mathrm{kPa}$, cyclic shear strain amplitude $1 \%$, and 10th cycle) [29].

tween these two works is the method by which the soil specimens are prepared in a specific unsaturated state and tested. Figure 13 compares the results in terms of $G$ versus $S_{r}$. The highlighted ellipse of drained tests in the figure shows that the effects of $S_{r}$ on $G$ in the $w$-controlled method are much lower than those in the $\psi$-controlled method. In fact, the effects of $S_{r}$ on $G$ are negligible in the $w$-controlled method. Moreover, Kim et al. [25] reached the same conclusion by carrying out resonant column tests on a well-graded sand. In order to obtain the same void ratio when employing $w$ controlled method, more compaction energy should be used at lower water contents due to the corresponding higher $\psi$, and this is the reason for the major principal directions of soil particles to be more horizontal and hence, be parallel at lower water contents, which can contribute to a reduction in stiffness. On the other hand, lower water contents are corresponding to higher $\psi$ values, resulting in higher stiffness. These two opposite phenomena, therefore, make the variations in

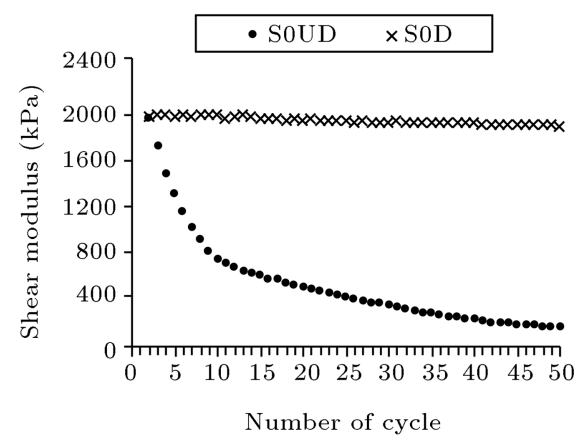

(a)
$G$ almost insensitive to changes in $S_{r}$ in testing based on the $w$-controlled method.

\subsection{Effects of drainage conditions}

In the fully saturated state, i.e., zero $\psi$, and adjacent to the groundwater table, soil drainage conditions are not straightforward (tests S0D and S0UD in Figure 3). In-situ drainage conditions under dynamic loadings are a function of soil permeability parameters (e.g., soil type, void ratio, and $S_{r}$ ), shearing rate, and boundary conditions [60]. As a result, the boundary drainage conditions can vary from a completely undrained to fully drained condition. In this study, the effects of boundary conditions for a sand with specific permeability and loading conditions were evaluated. In order to examine this influence, two tests were carried out on saturated specimens with zero $\psi$ under drained and undrained conditions. Figure 14(a) and (b) compare the dynamic parameters of sand in zero $\psi$ state under drained and undrained conditions. The drainage conditions of test SOD were considered drained on the top and undrained on the bottom and sides of specimen. In these conditions, the generation of porewater pressure and compression can occur simultaneously. It is noteworthy that pore-water cannot be fully drained due to the moderately high frequency of cyclic loading (i.e., $1 \mathrm{~Hz}$ ). Consequently, there is a drop in effective stress, while relative density rises. These two opposite effects neutralize each other, and $G$ and $D$ remain approximately constant with $N$. The second test SOUD, on the other hand, was done under undrained conditions. Because of generating excess pore-water pressure and reducing effective stress under fully undrained conditions, $G$ decreases and $D$ increases upon an increase in $N$. These observations provide an insight into the significance of drainage conditions on dynamic properties under cyclic loading and several uncertainties involved to precisely define boundary conditions for a saturated soil element nearby the groundwater table. Given that investigating the cyclic behavior of sand under different drainage conditions is

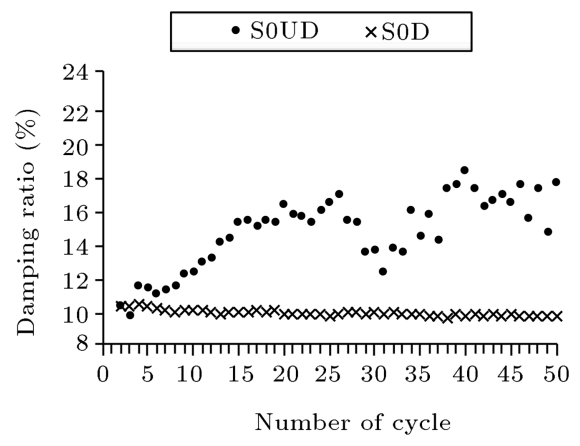

(b)

Figure 14. Comparison of variations in dynamic properties between drained and undrained tests at zero $\psi$ : (a) $G$ versus $N$ and (b) $D$ versus $N$. 
not the main objective of the current study, further research is required.

\subsection{Effects of number of loading cycles}

The similarity observed between the variations in dynamic properties with suction (Figure 9) and degree of saturation (Figure 11) in different cycles implies that $N$ does not have a significant effect on the trends of $G$ and $D$ versus $\psi$ and $S_{r}$. Although there is no experimental research on the effects of $N$ on specimens with the same initial fabrics under the $\psi$-controlled condition, these trends of cyclic parameters against $N$ have been shown under $w$-controlled conditions [29]. According to Figure $7(\mathrm{a})$, in all experiments except zero $\psi, G$ rises to a certain limit with $N$. These variations are almost similar and $G$ increases by about $9 \%$ ( 5 to $11 \%$ ) at the end of the 50th cycle. In contrast, $D$ decreases to a specific amount with $N$ in all $\psi$ (Figure $7(\mathrm{~b})$ ). These variations are similar and limited to about $3 \%$ in all experiments. This is essentially due to the growth in soil relative density or the drop in void ratio to a certain state by increasing $N$ (Figure 8 ). It is worth noting that differences in initial void ratio, shown in Table 4, are essentially negligible. Hence, specimens with a similar initial fabric tend to achieve nearly the same void ratio of 0.71 in all tests independent of the unsaturated states.

Soil settlement arising from cyclic loading is one of the main issues of geotechnical earthquake research because it has been recognized as a significant cause of damage in seismic events [61]. Figure 15(a) exhibits the settlement of unsaturated sand against the logarithm of $N$ for different $\psi$ values. In the figure, the sample relative settlement is equal to the total vertical strain at the end of each cycle multiplied by the initial height of sample at the beginning of the cyclic stage. The nearly linear trends in the semi-log plot of Figure 15(a) reveal the logarithmic relation between settlement and $N$, which is consistent with the observations of Duku et al. [62]. However, in contrast to their conclusions about the saturation level not influencing the cyclic compression behavior of sand, the cumulative settlements measured in this study are suction dependent. For example, the cumulative settlement is tripled once suction reduces from $80 \mathrm{kPa}$ (S80D) to zero (S0D) according to Figure 15(a). However, the amount of final settlement is not considerable at all suction levels. Due to the relatively small settlement, which is at most $1 \%$, the variations in void volume are small; therefore, $S_{r}$ stays almost constant in the cyclic stage (Figure $15(\mathrm{~b}))$ and it was illustrated by Milatz and Grabe [14] who observed that $S_{r}$ was approximately the same at the beginning and the end of shearing stage (Cycle 100) in unsaturated cyclic tests.

The pore-air and pore-water pressures were continuously measured at the sample boundaries through

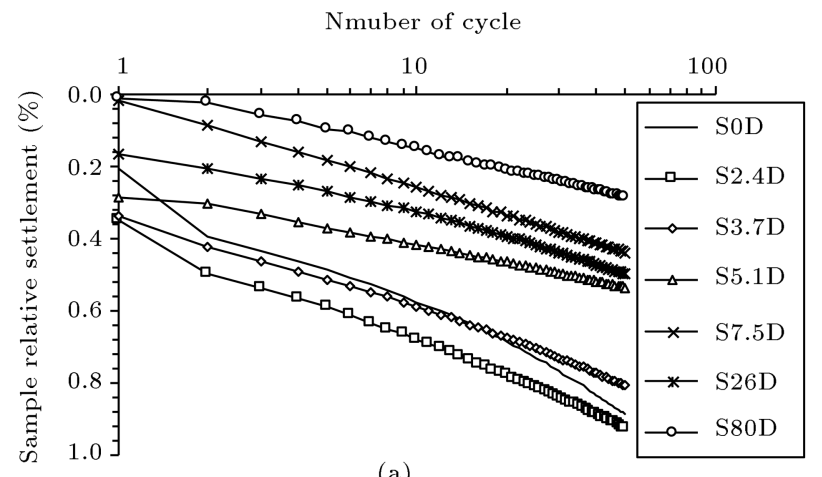

(a)

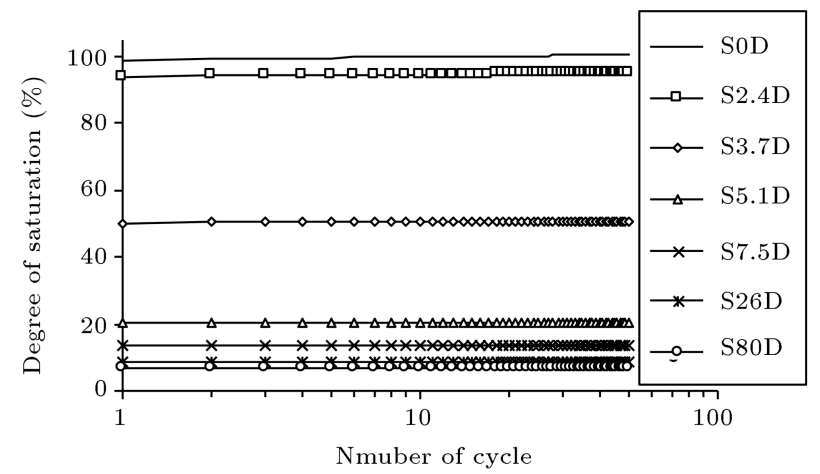

(b)

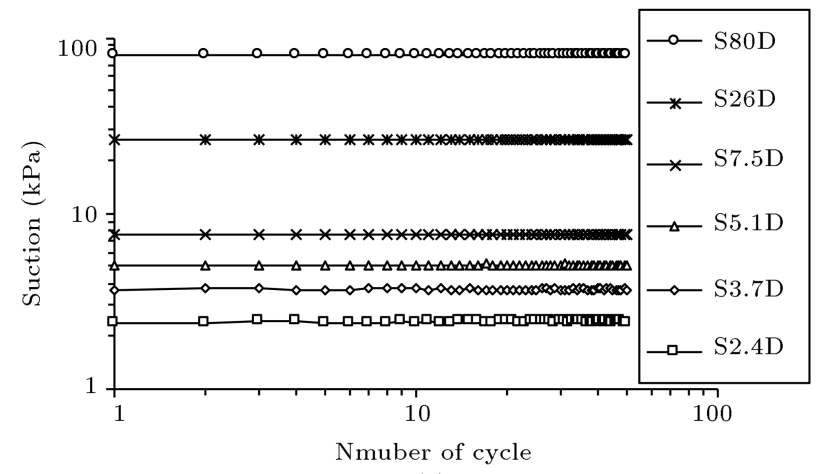

(c)

Figure 15. Effects of $N$ on (a) sample settlement, (b) $S_{r}$, and (c) $\psi$ at different suction values.

pressure transducers (Figure 1). As a result, the average suction at the end of each cycle can be evaluated and reported, as shown in Figure 15(c). According to the results, minor variations in suction occurred in the cyclic stage at all the suction levels examined in this study. Although cyclic tests were run under constant water condition, results of Figure 15(c) confirm that the suction also remained almost constant during cyclic tests, most probably due to the negligible volume change and degree of saturation.

\section{Conclusions}

The effects of initial suction $(\psi)$ and saturation degree $\left(S_{r}\right)$ on the cyclic behavior of unsaturated sand were investigated by conducting a series of cyclic simple shear 
tests at a large strain amplitude of $1 \%$ and a frequency of $1 \mathrm{~Hz}$. While initial fabric, net vertical stress, and void ratio of all specimens were kept almost the same before shearing, initial $\psi$ and $S_{r}$ values of specimens were controlled so as to cover all regions of the Soil Water Retention Curve (SWRC) including Capillary Zone (CZ), Transition Zone (TZ), and Residual Zone (RZ). Results were analyzed and interpreted to clarify the effects of initial $\psi$, initial $S_{r}$, unsaturated testing method, drainage conditions, and cyclic number $(N)$ on shear modulus $(G)$ and damping ratio $(D)$.

When $\psi$ increases, the gradual grow of $G$ is followed by a sharp rise and a slight decrease, in $\mathrm{CZ}$, TZ, and RZ, respectively. At $S_{r}$ close to the saturated state, a small change in $S_{r}$ has a relatively noticeable effect on $G$. At lower $S_{r}$ levels, $G$ increases significantly to a peak and then, decreases within RZ. Negligible variations in $D$ were found with changes in $\psi$ and $S_{r}$ in $\mathrm{CZ}$. However, $D$ reduces to its minimum value in $\mathrm{RV}$, which does not correspond to the maximum shear modulus. This is most likely due to the contribution of other mechanisms including water lubrication with a similar influence to the plasticity index on damping characteristics. $G$ grows and $D$ slumps to asymptotic levels with $N$ in all $\psi$ values, except zero, depending on suction state. These changes follow relatively similar trends independent of $\psi$, suggesting that $\psi$ does not have a significant effect on the trend of sand dynamic properties against loading cycles. Soil settlement has an almost linear relationship with logarithm of $N$ and $N$ has no significant effect on $S_{r}$ in the range of 10 to $90 \%$. At zero $\psi$, in the drained condition, the two opposite interactions of effective stress and relative density counterbalance each other and dynamic properties stay approximately constant with $N$. However, under undrained conditions, $G$ fell and $D$ climbed with $N$. This behavior foreshadows the generated excess pore-water pressure and consequently, a reduction in effective stress and stiffness. The impact of soil moisture change on $G$ in the $w$-controlled method was much lower than $\psi$-controlled, which should be considered in the dynamic testing on unsaturated soils.

\section{Acknowledgments}

The authors wish to thank Farideh Bouriazadeh for literary editing of this manuscript. The last author would also like to express his sincere gratitude to Sharif University of Technology and Iran's National Elites Foundation for financially supporting him as a visiting Assistant Professor.

\section{References}

1. Rahnema, H., Hashemi Jokar, M., and Khabbaz, H. "Predicting the effective stress parameter of un- saturated soils using adaptive neuro-fuzzy inference system", Sci. Iran., 26(6), pp. 3140-3158 (2019).

2. Lu, N. and Likos, W.J., Unsaturated Soil Mechanics, Jhon Wiley \& Sons Inc, New Jersey (2004).

3. Fredlund, D.G., Rahardjo, H., and Fredlund, M.D., Unsaturated Soil Mechanics in Engineering Practice, John Wiley \& Sons (2012).

4. Wheeler, S.J., Sharma, R.S., and Buisson, M.S.R. "Coupling of hydraulic hysteresis and stress-strain behaviour in unsaturated soils", Géotechnique, 53(1), pp. 41-54, Feb. (2003).

5. Sadeghi, H., Chiu, A.C.F., Ng, C.W.W., and Jafarzadeh, F. "A vacuum-refilled tensiometer for deep monitoring of in-situ pore water pressure", Scientia Iranica, 27(2), pp. 596-606 (2020).

6. Sivakumar, V. and Wheeler, S.J. "Influence of compaction procedure on the mechanical behaviour of an unsaturated compacted clay. Part 1: Wetting and isotropic compression", Gèotechnique, 50(4), pp. 359368 (2000).

7. Ng, C.W.W., Baghbanrezvan, S., Sadeghi, H., et al. "Effect of specimen preparation techniques on dynamic properties of unsaturated fine-grained soil at high suctions", Can. Geotech. J., 54(9), pp. 1310-1319 (2017).

8. Khalili, N. and Khabbaz, M.H. "A unique relationship of chi for the determination of the shear strength of unsaturated soils" , Geotechnique, 48(5), pp. 681-687 (1998).

9. Schnellmann, R., Rahardjo, H., and Schneider, H.R. "Controlling parameter for unsaturated soil property functions: validated on the unsaturated shear strength", Can. Geotech. J., 52(3), pp. 374-381 (2014).

10. Hossain, M.A. and Yin, J.-H. "Shear strength and dilative characteristics of an unsaturated compacted completely decomposed granite soil", Can. Geotech. J., 47(10), pp. 1112-1126 (2010).

11. Jokar, M.H. and Mirasi, S. "Using adaptive neurofuzzy inference system for modeling unsaturated soils shear strength", Soft Comput, 22(13), pp. 4493-4510 (2018).

12. Jokar, M.H., Khosravi, A., Heidaripanah, A., et al. "Unsaturated soils permeability estimation by adaptive neuro-fuzzy inference system", Soft Comput., pp. 1-11 (2018).

13. Delage, P. "Experimental unsaturated soil mechanics", 3rd International Conference on Unsaturated Soils, 3, pp. 973-996 (2002).

14. Milatz, M. and Grabe, J. "A new simple shear apparatus and testing method for unsaturated sands", Geotech. Test. J., 38(1), pp. 9-22 (2015).

15. Hardin, B.O. and Drnevich, V.P. "Shear modulus and damping in soil: measurement and parameter effects", J. Soil Mech. Found. Div., 98(7), pp. 667-692 (1972). 
16. Tatsuoka, F., Iwasaki, T., Yoshida, S., et al. "Shear modulus and damping by drained tests on clean sand specimens reconstituted by various methods", SOILS Found., 19(1), pp. 39-54 (1979).

17. Wu, S., Gray, D.H., and Richart, F.E. "Capillary effects on dynamic modulus of sands and silts", $J$. Geotech. Eng., 110(9), pp. 1188-1203 (1984).

18. Cabarkapa, Z., Cuccovillo, T., and Gunn, M. "Some aspects of the pre-failure behaviour of unsaturated soil", Second International Symposium on Prefailure Deformation Characteristics of Geomaterials, pp. 159165 (1999).

19. Sawangsuriya, A., Edil, T.B., Bosscher, P.J., et al. "Small-strain stiffness behavior of unsaturated compacted subgrade", in Unsaturated Soils, pp. 1121-1132 (2006).

20. Alramahi, B., Alshibli, K.A., Fratta, D., et al. "A suction-control apparatus for the measurement of $\mathrm{P}$ and S-wave velocity in soils", Geotech. Test. J., 31(1), p. 100646 (2008).

21. Ng, C.W.W., Xu, J., and Yung, S.Y. "Effects of wetting-drying and stress ratio on anisotropic stiffness of an unsaturated soil at very small strains", Can. Geotech. J., 46(9), pp. 1062-1076 (2009).

22. Nyunt, T.T., Leong, E.C., and Rahardjo, H. "Strength and small-strain stiffness characteristics of unsaturated sand", Geotech. Test. J., 34(5), pp. 1-11 (2011).

23. Hoyos, L.R., Suescún-Florez, E.A., and Puppala, A.J. "Stiffness of intermediate unsaturated soil from simultaneous suction-controlled resonant column and bender element testing", Eng. Geol., 188, pp. 10-28 (2015).

24. Mancuso, C., Vassallo, R., and d'Onofrio, A. "Small strain behavior of a silty sand in controlled-suction resonant column-torsional shear tests", Can. Geotech. J., 39(1), pp. 22-31 (2002).

25. Kim, D.S., Won-Seok, S., and Kim, M.-J. "Deformation characteristics of soils with variation of capillary pressure and water content", Soils Found., 43(4), pp. 71-79 (2003).

26. Khosravi, A., Ghayoomi, M., McCartney, J., et al. "Impact of effective stress on the dynamic shear modulus of unsaturated sand", Proc., GeoFlorida, 199(1), pp. 3052-3061 (2010).

27. Biglari, M., d'Onofrio, A., Mancuso, C., et al. "Smallstrain stiffness of Zenoz kaolin in unsaturated conditions" , Can. Geotech. J., 49(3), pp. 311-322 (2012).

28. Ishihara, K. "Soil behavior in earthquake geotechnics", Oxford Science Publication UK (1996).

29. Jafarzadeh, F. and Sadeghi, H. "Experimental study on dynamic properties of sand with emphasis on the degree of saturation", Soil Dyn. Earthq. Eng., 32(1), pp. 26-41 (2012).

30. Yang, S., Lin, H., Kung, J.H.S., et al. "Suctioncontrolled laboratory test on resilient modulus of unsaturated compacted subgrade soils", J. Geotech. Geoenvironmental Eng., 134(9), pp. 1375-1384 (2008).
31. Biglari, M., Jafari, M.K., Shafiee, A., et al. "Shear modulus and damping ratio of unsaturated kaolin measured by new suction-controlled cyclic triaxial device", Geotech. Test. J., 34(5), pp. 1-12 (2011).

32. Ghayoomi, M., Suprunenko, G., and Mirshekari, M. "Cyclic triaxial test to measure strain-dependent shear modulus of unsaturated sand", Int. J. Geomech., 7(9), p. 04017043 (2017).

33. Le, K.N. and Ghayoomi, M. "Cyclic direct simple shear test to measure strain-dependent dynamic properties of unsaturated sand", Geotech. Test. J., 40(3), pp. 381-395 (2017).

34. Jafarzadeh, F. and Sadeghi, H. "Dynamic properties of sand in constant-volume and constant-load tests", Fifth International Conference on Recent Advances in Geotechnical Earthquake Engineering and Soil Dynamics, p. 11 (2010).

35. Vassallo, R., Mancuso, C., and Vinale, F. "Effects of net stress and suction history on the small strain stiffness of a compacted clayey silt" , Can. Geotech. J., 44(4), pp. 447-462 (2007).

36. Wichtmann, T. and Triantafyllidis, T. "Influence of a cyclic and dynamic loading history on dynamic properties of dry sand, part II: Cyclic axial preloading", Soil Dyn. Earthq. Eng., 24(11), pp. 789-803 (2004).

37. Shahnazari, H., Heshmati, A.A., and Sarbaz, H. "Effect of cyclic pre-straining on the dynamic behavior of very dense sand", KSCE J. Civ. Eng., 19(1), pp. 63-73 (2015).

38. Khalili, N. and Zargarbashi, S. "Influence of hydraulic hysteresis on effective stress in unsaturated soils", Géotechnique, 60(9), pp. 729-734 (2010).

39. Toll, D. "The influence of fabric on the shear behaviour of unsaturated compacted soils", Adv. Unsaturated Geotech., 639798, pp. 222-234 (2000).

40. Brooks, R. and Corey, A. "Hydraulic properties of porous media", Hydrol. Pap. Color. State Univ., 3, March, p. 37 (1964).

41. Van Genuchten, M.T. "A closed-form equation for Predicting the hydraulic conductivity of unsaturated soils", Soil Sci. Soc. Am. J., 44(5), p. 892 (1980).

42. Fredlund, D.G. and Xing, A. "Equations for the soilwater characteristic curve", Can. Geotech. J., 31(4), pp. 521-532 (1994).

43. Vanapalli, S.K., Sillers, W.S., and Fredlund, M.D. "The meaning and relevance of residual state to unsaturated soils", Proc. 51st Can. Geotech. Conf., pp. $1-8$ (1998).

44. ASTM D3999-11e1, "Standard test methods for the determination of the modulus and damping properties of soils using the cyclic triaxial apparatus", Am. Soc. Test. Mater., no. Reapproved, pp. 1-16 (2011).

45. Toyota, H. and Takada, S. "Technique for undrained triaxial tests on unsaturated soils using active control of pore-air pressure", Geotech. Test. J., 35(3), pp. 480489 (2012). 
46. Sze, H.Y. and Yang, J. "Failure modes of sand in undrained cyclic loading: Impact of sample preparation", Geotech. Geoenvironmental Eng., 140(1), pp. 152-169 (2014).

47. Thom, R., Sivakumar, V., Brown, J., et al. "A simple triaxial system for evaluating the performance of unsaturated soils under repeated loading", Geotech. Test. J., 31(2), pp. 107-114 (2008).

48. Kammerer, A.M., Wu, J., Riemer, M.F., et al. "Use of cyclic simple shear testing in evaluation of the deformation potential of liquefiable soils", 4th Int. Conf. Recent Adv. Geotech. Earthq. Eng. Soil Dyn., pp. 26-31 (2001).

49. Lu, N., Wu, B., and Tan, C.P. "Tensile strength characteristics of unsaturated sands", J. Geotech. Geoenvironmental Eng., 133(2), pp. 144-154 (2007).

50. Lu, N. and Likos, W.J. "Suction stress characteristic curve for unsaturated soil", J. Geotech. Geoenvironmental Eng., 132(2), pp. 131-142 (2006).

51. Wang, Y.H. and Santamarina, J.C. "Attenuation in sand: An exploratory study on the small-strain behavior and the influence of moisture condensation", Granul. Matter, 9(6), pp. 365-376 (2007).

52. Cho, G.C. and Santamarina, J.C. "Unsaturated particulate materials-particle-level studies", J. Geotech. Geoenvironmental Eng., 127(1), pp. 84-96 (2001).

53. Yoshida, N., Seismic Ground Response Analysis, 36 Dordrecht: Springer Netherlands (2015).

54. Zhang, J., Andrus, R.D., and Juang, C.H. "Normalized shear modulus and material damping ratio relationships", J. Geotech. Geoenvironmental Eng., 131(4), pp. 453-464 (2005).

55. Khosravi, A. and McCartney, J.S. "Impact of hydraulic hysteresis on the small-strain shear modulus of low plasticity soils", J. Geotech. Geoenvironmental Eng., 138(11), pp. 1326-1333 (2012).

56. Tsukamoto, Y., Ishihara, K., Nakazawa, H., et al. "Resistance of partly saturated sand to liquefaction with reference to longitudinal and shear wave velocities", Soils Found., 42(6), pp. 93-104 (2002).

57. Okamura, M. and Soga, Y. "Effects of pore fluid compressibility on liquefaction resistance of partially saturated sand", Soils Found., 46(5), pp. 695-700 (2006).

58. Das, B.M. and Luo, Z., Principles of Soil Dynamics, Cengage Learning (2016).

59. Vaid Y.P. and Sivathayalan, S. "Static and cyclic liquefaction potential of Fraser Delta sand in simple shear and triaxial tests", Can. Geotech. J., 33(2), pp. 281-289 (1996).

60. Yang, Z. and Elgamal, A. "Influence of permeability on liquefaction-induced shear deformation", J. Eng. Mech., 128(7), pp. 720-729 (2002).

61. Wartman, J., Rodriguez-Marek, A., Repetto, P.C., et al. "Ground failure", Earthq. Spectra, 19(S1), pp. 3556 (2003).
62. Duku, P.M., Stewart, J.P., Whang, D.H., et al. "Volumetric strains of clean sands subject to cyclic loads", J. Geotech. Geoenvironmental Eng., 134(8), pp. 1073-1085 (2008).

63. Schmertmann, J.H. "Guidelines for cone penetration test: performance and design", No. FHWA-TS-78209, United States, Federal Highway Administration (1978).

64. Burmister, D.M. "Physical, stress-strain, and strength responses of granular soils", STP322-EB ed., P. Brown and W. Shockley, Eds., ASTM International, West Conshohocken, PA, pp. 67-97 (1962).

65. Kokusho, T. "Cyclic triaxial test of dynamic soil properties for wide strain ranges", Soils Found., 20(2), pp. 45-60 (1980).

\section{Biographies}

Fardin Jafarzadeh received his BSc and MSc in Civil Engineering from Tehran University and PhD from Tohoku University of Japan in 1996. Since then, he has been working as a full-time assistant and Associate Professor and a researcher at Sharif University of Technology, Tehran, Iran. He has taught more than 8 courses related to Civil and Geotechnical Engineering for $\mathrm{BSc}, \mathrm{MSc}$ and $\mathrm{PhD}$ students and supervised more than $60 \mathrm{MSc}$ and $8 \mathrm{PhD}$ students. Also, he has served as the Research Deputy of the Civil Engineering Department, the Head of the Geotechnical Eng. Group, and the Head of Advanced Soil Mechanics Laboratory. His main fields of research interests are soil dynamics, laboratory element and physical model tests, design of embankment dams, geotechnical earthquake engineering, unsaturated soil mechanics, geothermal piles, and ground improvement. The results of his research have been published in various technical journals and proceedings and presented in International conferences.

Adel Ahmadinezhad is a PhD candidate in Geotechnical Engineering at the Department of Civil Engineering at Sharif University of Technology, Tehran. His doctoral thesis mostly focuses on the dynamic properties of unsaturated soil, which is the extension of his research work in his MSc in the same institute. He has received his BSc in Civil Engineering from University of Kerman. His current research interests include unsaturated soil mechanics, geotechnical earthquake engineering, energy geostructures, and bio-geotechnical engineering. In 2015, he won the 18th Khwarizmi Young Award, the most prestigious scientific national award in Iran. He also holds four granted patents in the field of soil element testing. He received the Distinguished Postgraduate Research Student Award from the Department of Civil Engineering in 2016. 
Hamed Sadeghi is currently an Assistant Professor at the Department of Civil Engineering at Sharif University of Technology. He served the same institute as a Visiting Assistant Professor, a Research Assistant Professor, and a Post-doctoral Research Fellow from 2016 to 2018 . He obtained all his degrees with firstclass honors and is the first graduate of the DualDegree PhD Program between the Hong Kong University of Science \& Technology and Sharif University of Technology in all disciplines with notable research and educational distinction. He has published more than 30 journal and conference articles and has been a frequent reviewer for about 15 peer-reviewed ISI journals. His research has been mainly focused on unsaturated soil mechanics, geotechnical earthquake engineering, and development of advanced laboratory techniques. His research laboratory tries to advance reliable characterization and theorizing complex multiphase flow through deformable porous media.

He has received several awards including the distinguished university student in the 26th outstanding student award, the Dr Tavakoli Prize for the best $\mathrm{PhD}$ thesis in Civil Engineering, the representative $\mathrm{PhD}$ graduate in the university graduation ceremony, the distinguished postgraduate research student at the Department of Civil Engineering, the post-doctoral research fellowship, the development grant, the travel grant, and some more from Iran's National Elites Foundation (INEF), the full PhD scholarship and travel grants from the government of Hong Kong Special Administrative Region (HKSAR), two research grants from Sharif Research and Technology Office, and the top five national research project-based military service award. 